\title{
EARLY VS LATE CAFFEINE THERAPY IN PRETERM INFANTS: ANALYSIS OF CLINICAL OUTCOME
}

\author{
Hafsa Niaz, Jawad Jalil*, Muhammad Adil**, Faisal Basheer*, Shahzad Akhtar*, Naila Hamid
}

Pak Emirates Military Hospital/National University of Medical Sciences (NUMS) Rawalpindi Pakistan, *Combined Military Hospital/National University of Medical Sciences (NUMS) Rawalpindi Pakistan, ${ }^{* *}$ Combined Military Hospital Skardu/National University of Medical Sciences (NUMS) Rawalpindi Pakistan

\section{ABSTRACT}

Objective: To study clinical outcome of early versus late caffeine therapy in preterm infants.

Study Design: Prospective comparative study.

Place and Duration of Study: Neonatal Intensive Care Unit, Pak Emirates Military Hospital, Rawalpindi, from Jan to Jul 2018.

Methodology: A total of 40 preterm infants with gestational age $<32$ weeks and birth weight $<1500$ grams were randomly divided into two groups on the basis of initiation of caffeine therapy i.e. group A (early caffeine group) and group B (late caffeine group). Infant's demographic data and clinical outcomes were compared between both groups using SPSS IBM software.

Results: Mean gestational age was $29.9 \pm 1.19$ weeks with male to female ratio of 1.5:1 Mean birth weight was $1165.3 \pm 316$ grams. Half $(50 \%)$ of the infants were delivered by cesarean section while surfactant was given in $29(72.5 \%)$ infants. While comparing both groups we observed that early caffeine shortens duration of Neonatal Intensive Care Unit stay $(p<0.05)$ whereas caffeine therapy initiation timings didn't influence the risk of development of Respiratory Distress Syndrome or need of mechanical ventilation.

Conclusion: Early caffeine therapy in preterm infants is associated with decrease duration of Neonatal Intensive Care Unit stay. However further work is needed in this regards to establish its efficacy and safety.

Keywords: Caffeine therapy, Neonatal intensive care unit, Preterm infants.

This is an Open Access article distributed under the terms of the Creative Commons Attribution License (http://creativecommons.org/licenses/by/4.0), which permits unrestricted use, distribution, and reproduction in any medium, provided the original work is properly cited.

\section{INTRODUCTION}

Over the last four decades, methylxanthines are commonly prescribed in preterm babies for apnea ${ }^{1}$. Kuzemko and Paala were the pioneer to document the use of aminophylline for the treatment of apnea in preterm infants in 1973. However Aranda et al for the first time used caffeine successfully for apnea in preterm infants ${ }^{2}$. Over the period of time a lot of work has been done to rationalize the role of caffeine in apnea of prematurity. However major breakthrough was Caffeine for Apnea of Prematurity (CAP) trial, one of its own kind international multicenter trial which well established the role of caffeine to prevent adverse pulmonary events in preterm infants ${ }^{3}$.

Apnea is a common presentation in preterm infants because of poorly developed respiratory control mechanism. It is one of the most common diagnosis in neonatal intensive care units. Its incidence increases with decreasing gestational age and birth weight, affecting about $25 \%$ of infants under $2.5 \mathrm{~kg}$ while $80 \%$ under $1 \mathrm{~kg}^{4}$. Similarly the chances of having apnea is about $100 \%$ in all infants born at $\leq 28$ weeks of gestation while its incidence decreases from $85 \%$ in infants born at 30 weeks of gestation to $20 \%$ in infants born at

Correspondence: Dr Hafsa Niaz, Department of Paediatrics, Pak Emirates Military Hospital, Rawalpindi Pakistan

Received: 23 Jan 2020; revised received: 01 May 2020; accepted: 08 May 2020
34 weeks of gestation. This associations has clinical implications i.e. all infants delivered prematurely will need cardio pulmonary monitoring in intensive care units. Infants with apnea are at increased risk of intracranial bleed, pulmonary failure, cardiovascular problems, poor mental growth and death ${ }^{5}$. Therefore timely and effective management not only reduced disability rate but also mortality.

Caffeine owing to its efficacy, admissibility, wider safety margin and therapeutic index with longer half-life has become mainstay of treatment for preterm infants with apnea ${ }^{6}$. It is also effective in reducing the rate of bronchopulmonary dysplasia and has been shown to increases survival rate of very low birth weight babies (18-21 months) without any neurodevelopmental disability ${ }^{7}$. Although clinical effectiveness of caffeine has been confirmed and practiced world while yet its absolute efficacy has to be established in our clinical setup. This will not only improve patient health but also inculcate a process of evaluation and evolution. Keeping this in mind we conducted a study that analyze the clinical outcome of early versus late initiation of caffeine therapy in preterm infants.

\section{METHODOLOGY}

This prospective comparative study was conducted at Neonatal Intensive Care Unit (NICU) of Pak 
Emirates Military Hospital, Rawalpindi from Jan 2018 to Jul 2018. Approval was taken from Hospital Ethics Committee before the start of study. We selected 40 preterm infants with gestational age $<32$ weeks and birth weight $<1500$ grams delivered at our center during the study period. Infants with major congenital anomaly or those requiring emergent endotracheal intubation immediately after birth were excluded from the study. Informed written consent was obtained from all parents. Infants were selected by non-probability consecutive sampling. They were randomly assigned to one of the two treatment groups in 1:1 ratio using lottery method i.e. group A which was early caffeine group and group B which was late caffeine group. Each group ended up with 20 preterm infants.

Clinical outcomes of caffeine therapy were compared among both groups. Both groups were defined on the basis of timing of initiation of caffeine therapy with 'early' group with infants in which caffeine was administered before third day of life while 'late' group caffeine was started after third day of life. The day of life on which infant receive his first dose of caffeine determines initiation of caffeine therapy with day of birth being considered as 0 day of life (DOL). Early caffeine regimen consisted of loading dose of $20 \mathrm{mg} /$ $\mathrm{kg}$ given intravenously on the first or second DOL whereas late caffeine regimen consisted of the same dose given between third and seven DOL. While maintenance dose of caffeine was $5 \mathrm{mg} / \mathrm{kg}$ intravenously once daily ${ }^{8,9}$. studied are duration of stay in Neonatal Intensive Care Unit (NICU), need of mechanical ventilation and development of Respiratory Distress Syndrome (RDS). RDS was diagnosed on the basis of clinical signs and symptoms (tachypnea, central cyanosis, chest in drawings, nasal flaring, and grunting) and radiologically by chest radiograph. All data was analyzed using SPSS IBM software. Frequencies and percentages were calculated for all categorical variables. Mean SD were calculated for all numerical variables. Fisher's exact test (for categorical variables) and unpaired t-test (numerical variables) were used. The $p$-value $\leq 0.05$ was considered significant.

\section{RESULTS}

A total of 40 preterm infants with mean gestational age $29.9 \pm 1.19$ weeks were included in the study. Mean birth weight was $1165.3 \pm 316$ grams. Forty preterm infants were included in the study out of which 20 received early caffeine i.e, within 1-2 DOL and 20 received late caffeine i.e. 3-7 DOL. In early caffeine group $11(55 \%)$ of the infants were delivered by SVD while $9(45 \%)$ were born by cesarean section. In late caffeine group $9(45 \%)$ were delivered via SVD and $11(55 \%)$ were born by cesarean section. Surfactant was given in $13(65 \%)$ infants of early caffeine group and $16(80 \%)$ of late caffeine group. Following demographic characteristics like age, sex, birth weight, mode of delivery and use of surfactant were evaluated as shown in table-I.

Table-I: Characteristics of infants.

\begin{tabular}{|c|c|c|c|}
\hline Variable & $\begin{array}{l}\text { Early Caffeine Group } \\
\text { (1-2 Day of Life) } n=20\end{array}$ & $\begin{array}{l}\text { Late Caffeine Group } \\
\text { (3-7 Day of Life) } n=20\end{array}$ & $p$-value \\
\hline Gestational age (Weeks) & $29.84 \pm 1.16$ & $29.96 \pm 1.23$ & 0.735 \\
\hline \multicolumn{4}{|l|}{ Gender } \\
\hline $\begin{array}{l}\text { Male } \\
\text { Female }\end{array}$ & $\begin{array}{c}11(55 \%) \\
9(45 \%)\end{array}$ & $\begin{array}{c}13(65 \%) \\
7(35 \%)\end{array}$ & 0.748 \\
\hline Birth Weight (Grams) & $1149.35 \pm 373.84$ & $1181.25 \pm 259.75$ & 0.756 \\
\hline \multicolumn{4}{|l|}{ Mode of Delivery } \\
\hline $\begin{array}{l}\text { Vaginal Delivery } \\
\text { Cesarean Section }\end{array}$ & $\begin{array}{c}11(55 \%) \\
9(45 \%)\end{array}$ & $\begin{array}{c}9(45 \%) \\
11(55 \%)\end{array}$ & 0.752 \\
\hline Surfactant & $13(65 \%)$ & $16(80 \%)$ & 0.480 \\
\hline
\end{tabular}

Duration of caffeine therapy is still debatable but generally it is considered that after 34 weeks of gestation apnea is unlikely so can discontinue after 3436 weeks with apnea free episodes of 8 days ${ }^{10}$. In our study we continued caffeine therapy till 34 weeks.

Data of all infants including gestational age, gender, birth weight, mode of delivery and use of surfactant was collected. Infant's outcome which were
Outcomes which were studied in this study are duration of stay in NICU, need of mechanical ventilation and development of Respiratory Distress Syndrome (RDS). In early caffeine group the duration of NICU stay was $22.25 \pm 12.64$ days while in late caffeine group the NICU stay was of $35.95 \pm 22.06$ days showing $p$-value of $0.021 .14(70 \%)$ infants in early group required mechanical ventilation while $16(80 \%)$ in late 
caffeine group were ventilated, $p$-value came out to be 0.716 . Similarly $14(70 \%)$ and $16(80 \%)$ of patients in early and late caffeine group developed RDS. Outcome is shown in table-II. nary monitoring due to immature respiratory control mechanism, resulting in longer hospital duration and ultimately significant rise in health care $\operatorname{cost}^{14}$. Majority of studies done on premature babies and very

Table-II: Clinical outcome.

\begin{tabular}{l|c|c|c}
\hline Variable & $\begin{array}{c}\text { Early Caffeine Group } \\
\text { (1-2 Day of Life) }\end{array}$ & $\begin{array}{c}\text { Late Caffeine Group } \\
\text { (3-7 Day of Life) }\end{array}$ & $\boldsymbol{p}$-value \\
\hline Hospital Stay (Days) & $22.25 \pm 12.64$ & $35.95 \pm 22.06$ & 0.021 \\
Mechanical Ventilation & $14(70 \%)$ & $16(80 \%)$ & 0.716 \\
Respiratory Distress Syndrome & $14(70 \%)$ & $16(80 \%)$ & 0.716 \\
\hline
\end{tabular}

\section{DISCUSSION}

It was a single center study designed to evaluate the efficacy of early versus late initiation of caffeine therapy in preterm infants. Third day of life was selected as the cutoff to divide the two groups, this was based on the median day of caffeine initiation as already done in CAP trial 2 . Forty preterm infants with maximum gestational of 32 weeks and a minimum gestational age of 27 weeks (mean gestational age 29.9 \pm 1.19 weeks) were included in the study. Preterm infant uptill 32 weeks were selected because apnea of prematurity is not common past 34 weeks gestation ${ }^{10}$. Male to female ratio was 1.5: 1 . Mean birth weight was $1165.3 \pm 316$ grams.

Half $(50 \%)$ of the infants were delivered by cesarean section and surfactant was given in 29 (72.5\%) infants. The rate of cesarean section in our study was comparable to international studies. In a study by Hand et al about $53.33 \%$ infants were delivered by cesarean section ${ }^{11}$. Caffeine regimen consisted of loading dose of $20 \mathrm{mg} / \mathrm{kg}$ given intravenously and maintenance dose of $5 \mathrm{mg} / \mathrm{kg}$ intravenously once daily ${ }^{8,9}$. It was given till the baby reached 34 weeks of gestation $^{10}$. While comparing both groups we didn't observe any statistical difference in demographic characteristics like age, gender, birth weight, mode of delivery and use of surfactant.

We observed significant statistical difference when we analyzed duration of NICU stay between both study groups. In early caffeine group the duration of NICU stay was $22.25 \pm 12.64$ days while in late caffeine group the NICU stay was of $35.95 \pm 22.06$ days showing $p$-value of 0.021 . Several studies have suggested the role of early caffeine therapy in decreasing the NICU stay. In our study early caffeine group is associated with decreased hospital stay. Similar findings were published by Dobson et al and Patel et al ${ }^{12,13}$. This is because of the fact that apnea of prematurity needs respiratory support and often requires cardiopulmo- low birth weight babies showed that development of apnea is associated with increased hospital stay ${ }^{15}$.

Our study did not demonstrate a difference in the need for endotracheal intubation between both groups $(p=0.716)$. However early caffeine therapy improves pulmonary function by augmenting minute ventilation, muscle contractility and lung mechanics ${ }^{16}$. It facilitates early weaning off from ventilator support and leads to decrease in endotracheal ventilation. This potential benefit of caffeine has been supported by Muhammad et al, Rhein et al and many other authors ${ }^{17,18}$. Similarly CAP trial has clearly demonstrated a reduction in mechanical ventilation by one week by use of caffeine ${ }^{19}$.

No statistical difference was seen when comparing the development of respiratory distress syndrome between early and late group $(p=0.716)$. However in recent studies, emphasis is made on use of caffeine in infants with RDS to minimize the need of mechanical ventilation ${ }^{20}$. Similarly a prospective cohort study by Hand et al in year 2016 on infants with RDS showed that early initiation of caffeine therapy is associated with lower rate of intraventricular hemorrhage and decrease need of ventilation ${ }^{11}$. But our study didn't show any significant difference with early or late caffeine therapy including both decreasing need of mechanical ventilation and RDS. This difference may due to selection of patients or small sample size which affected the statistical power to detect any difference.

Improving the timings of caffeine therapy by commencing treatment at early or prophylactic use of caffeine may provide additional benefits over its conventional use in infants with apnea or prematurity or for facilitating extubation in preterms ${ }^{14}$. Our data at single center suggest that early initiation of caffeine therapy in preterm infants had substantial effect on clinical outcome as compared to delayed initiation. Although a lot of work has been done in this respect to support this evidence, still there is need of further 
randomized controlled trials to justify the prophylactic role of caffeine in preventing neonatal morbidities such bronchopulmonary dysplasia and patent ductus arteriosus. This will not only establish the role of caffeine prophylaxis but also safety of early caffeine therapy in extremely preterm infants ${ }^{14}$.

This study was a comparative study at one of the largest running NICU of Pakistan where all the deliveries were conducted by classified obstetrician and babies received by qualified pediatricians. All efforts were made to ensure that data collected was reliable. However owing to its small sample size and being conducted at a single center we were under powered to attain any significant differences in the clinical outcome of decreasing intubation and development of respiratory distress syndrome. Our clinical outcome can only be hypothetical until a full fledge randomized controlled trial be conducted encompassing multi centers and different sets of population. Secondly in our study we only included infants which were not intubated at birth, so we cannot justify whether early caffeine would have same hemodynamic effects on potentially sicker intubated infants. Given the enhanced procedures of hemodynamics it may be judicious to contain these infants in future trials of caffeine.

\section{CONCLUSION}

Early caffeine therapy in preterm infants is associated with decrease duration of NICU stay. However further work is needed in this regards to establish its absolute efficacy and safety in our clinical setup. This will not only improve patient outcome but also inculcate a process of evaluation and evolution.

\section{CONFLICT OF INTEREST}

This study has no conflict of interest to be declared by any author.

\section{REFERENCES}

1. Schmidt B, Davis PG, Roberts RS. Timing of caffeine therapy in very low birth weight infants. J Pediatrics 2014; 164(5): 957-58.

2. Kreutzer K, Bassler D. Caffeine for apnea of prematurity: a neonatal success story. Neonatology 2014; 105(4): 332-36.

3. Schmidt B. Methylxanthine therapy for apnea of prematurity: evaluation of treatment benefits and risks at age 5 years in the international Caffeine for Apnea of Prematurity (CAP) trial. Neonatol 2005; 88(3): 208-13.

4. Kumar S, Nayanam S. Observation on neonatal apnea in relation to aetiopathogensis and their outcome. Intl J Contemp Pediat 2017; 4(1): 249-53.

5. Ulanovsky I, Haleluya NS, Blazer S, Weissman A. The effects of caffeine on heart rate variability in newborns with apnea of prematurity. J Perinatol 2014; 34(8): 620.

6. Shrestha B, Jawa G. Caffeine citrate-Is it a silver bullet in neonatology?. Pediatrics Neonatol 2017; 58(5): 391-97.

7. Schmidt B, Roberts RS, Davis P, Doyle LW, Barrington KJ, Ohlsson A, et al. Long-term effects of caffeine therapy for apnea of prematurity. N Eng J Med 2007; 357(19): 1893-902.

8. Comer A, Perry C, Figgitt D. Caffeine Citrate. Paediat Drug 2001; 3(1): 61-79.

9. Leon AC, Michienzi $K$, , Hutchison A. Serum caffeine concentrations in preterm neonates. Am J Perinatol 2007; 24(1): 039-47.

10. Eichenwald EC. Apnea of prematurity. Pediatr 2016; 137(1): e20153757.

11. Patel RM, Leong T, Carlton DP, Vyas-Read S. Early caffeine therapy and clinical outcomes in extremely preterm infants. J Perinatol 2013; 33(2): 134.

12. Montenegro BL, Amberson M, Veit L, Freiberger C, Dukhovny D, Rhein LM. Economics of home monitoring for apnea in late preterm infants. Respiratory care 2017; 62(1): 42-48.

13. Bahari M, Aldana JC, Featherstone R, Kumar M. Caffeine use for apnea of prematurity in moderate and late preterm infants: A systematic review. J Clin Neonatol 2019; 8(3): 162.

14. Yoder B, Thomson M, Coalson J. Lung function in immature baboons with respiratory distress syndrome receiving early caffeine therapy: a pilot study. Acta Paediatr 2005; 94(1): 92-98.

15. Rhein LM, Dobson NR, Darnall RA, Corwin MJ, Heeren TC, Poets $\mathrm{CF}$, et al. Effects of caffeine on intermittent hypoxia in infants born prematurely: a randomized clinical trial. J Am Med Assoc Pediatr 2014; 168(3): 250-57.

16. Mohammed S, Nour I, Shabaan AE, Shouman B, Abdel-Hady H. High versus low-dose caffeine for apnea of prema-turity: a randomized controlled trial. Eur J Pediatr 2015; 174(7): 949-56.

17. Schmidt B, Roberts RS, Davis P, Doyle LW, Barrington KJ, Ohlsson A, et al. Caffeine therapy for apnea of prematurity. N Eng J Med 2006; 354(20): 2112-21.

18. Sweet DG, Carnielli V, Greisen G, Hallman M, Ozek E, te Pas A, et al. European consensus guidelines on the management of respiratory distress syndrome-2019 update. Neonatol 2019; 115(4): 432-50.

19. Hand I, Zaghloul N, Barash L, Parris R, Aden U, Li H. Timing of caffeine therapy and neonatal outcomes in preterm infants: a retrospective study. Intl J Pediatr 2016; 2016: 1-6.

20. Dobson NR, Patel RM, Smith PB, Kuehn DR, Clark J, Vyas-Read $\mathrm{S}$, et al. Tends in caffeine use and association between clinical outcomes and timing of therapy in very low birth weight infants. J Pediatr 2014; 164(5): 992-98. 